\title{
Partial deficiency of Thyroid transcription factor 1 produces predominantly neurological defects in humans and mice
}

Rapid Publication

See related Commentary

on pages 451-455.

\author{
Joachim Pohlenz, ${ }^{1,2}$ Alexandra Dumitrescu, ${ }^{2,3}$ Dorothee Zundel, ${ }^{4}$ Ursula Martiné, ${ }^{1}$ \\ Winfried Schönberger, ${ }^{1}$ Eugene Koo, ${ }^{2}$ Roy E. Weiss, ${ }^{2}$ Ronald N. Cohen, ${ }^{2}$ Shioko Kimura, ${ }^{5}$ \\ and Samuel Refetoff $2,3,6$
}

${ }^{1}$ Children's Hospital of Johannes Gutenberg University of Mainz, Mainz, Germany

${ }^{2}$ Department of Medicine, and

${ }^{3}$ Committee on Genetics, The University of Chicago, Chicago, Illinois, USA

${ }^{4}$ Sozialpädiatrisches Zentrum, Bad Kreuznach, Germany

${ }^{5}$ Laboratory of Metabolism, National Cancer Institute, Bethesda, Maryland, USA

${ }^{6}$ Department of Pediatrics, The University of Chicago, Chicago, Illinois, USA

Address correspondence to: Samuel Refetoff, University of Chicago, MC3090, 5841 S. Maryland Avenue, Chicago, Illinois 60637, USA. Phone: (773) 702-6939; Fax: (773) 702-6940; E-mail: refetoff@medicine.bsd.uchicago.edu.

Received for publication September 11, 2001, and accepted in revised form January 8, 2002.

Three genes, TTF1, TTF2, and PAX8, involved in thyroid gland development and migration have been identified. Yet systematic screening for defects in these genes in thyroid dysgenesis gave essentially negative results. In particular, no TTF1 gene defects were found in 76 individuals with thyroid dysgenesis even though a deletion of this gene in the mouse results in thyroid and lung agenesis and defective diencephalon. We report a 6 -year-old boy with predominant dyskinesia, neonatal respiratory distress, and mild hyperthyrotropinemia. One allele of his TTF1 gene had a guanidine inserted into codon 86 producing a nonsense protein of 407, rather than 371 , amino acids. The mutant TTF1 did not bind to its canonical cis-element or transactivate a reporter gene driven by the thyroglobulin promoter, a natural target of TTF1. Failure of the mutant TTF1 to interfere with binding and transactivation functions of the wild-type TTF1 suggested that the syndrome was caused by haploinsufficiency. This was confirmed in mice heterozygous for $T t f 1$ gene deletion, heretofore considered to be normal. Compared with wild-type littermates, $\mathrm{Tt} f 1^{+/-}$mice had poor coordination and a significant elevation of serum thyrotropin. Therefore, haploinsufficiency of the TTF1 gene results in a predominantly neurological phenotype and secondary hyperthyrotropinemia.

This article was published online in advance of the print edition.

The date of publication is available from the JCI website, http://www.jci.org.

J. Clin. Invest. 109:469-473 (2002). DOI:10.1172/JCI200214192.

\section{Introduction}

Congenital hypothyroidism occurs in 1:3,500-1:4,000 newborns (1). Serum thyrotropin (TSH) levels are elevated in the majority of cases, and, therefore, congenital hypothyroidism can be detected by neonatal screening programs. This allows for early initiation of thyroid hormone replacement to avert irreversible neurological and psychomotor damage. In $80-85 \%$ of the cases, congenital hypothyroidism is due to developmental abnormalities of the thyroid gland leading to thyroid dysgenesis (22-42\% agenesis, 35-42\% ectopia, and 24-36\% hypoplasia) (2). In the remaining $15-20 \%$, congenital hypothyroidism is associated with a goiter, is often familial, and is usually due to dyshormonogenesis, a defect in one of the well-characterized biochemical processes involved in thyroid hormone synthesis (1). While the genetic causes of most forms of thyroid dyshormonogenesis have been identified, little is known regarding the cause of thyroid dysgenesis.

Three genes encoding transcription factors have a major role in the development of the thyroid gland. These are $P A X 8, T T F 2$, and TTF1, whose functions have been recognized mainly through observations made in knockout mice.

PAX8 is a transcription factor belonging to a protein family that binds DNA via the paired domain (3). Expressed in the kidney and thyroid, it is implicated together with TTF1 in the tissue-specific expression of thyroglobulin and thyroperoxidase. In humans, $P A X 8$ maps to $2 \mathrm{q} 12-\mathrm{q} 14$ and consists of 11 exons. Mice lacking the Pax8 locus have no thyroid follicular cells and, if left untreated, die before 3 weeks of age (4). Two families and two isolated cases were found to have nonsense and missense mutations in one allele of the $P A X 8$ gene, resulting in hypothyroidism associated with thyroid hypoplasia and, in one case, ectopy $(5,6)$. TTF2, also known as TITF2 or FKHL15, belongs to the family of proteins that bind DNA through a "forkhead domain" (7). It is encoded by a single exon in human 9q22 (8). Mice lacking the Ttf2 locus (9) and two brothers homozygous for a missense mutation $(\mathrm{A} 65 \mathrm{~V})$ within the forkhead domain (10) show similar findings: severe hypothyroidism due to completely absent or sublingual thyroid gland and cleft palate.

TTF1, also called TITF1, T/EBP, and NKX2.1, is the prototype of a subfamily of transcription factors containing a homeobox domain. Ttf1-null mice lack thyroid glands, lungs, and pituitary glands and have defects in the 
ventral forebrain (11). The human gene, located in $14 \mathrm{q} 13$, is encoded by three exons and is transcribed from several start sites (12). The most abundant gene product, also found in the thyroid, is generated from an open reading frame contained in exons 2 and 3 and encoding 371 amino acids (12-14). TTF1 has multiple binding sites in the promoters and distant enhancers of the thyroglobulin and thyroid peroxidase genes and controls their expression in the adult thyroid gland (15). Two systematic surveys for defects in the TTF1 gene in subjects with thyroid dysgenesis yielded negative results $(16,17)$. However, one case with "compensated hypothyroidism" (high TSH but normal thyroxine $\left[\mathrm{T}_{4}\right]$ ), hypotonia, truncal ataxia, and respiratory failure had a 13-centi-Morgan deletion of chromosome 14, which included the TTF1 gene locus (18). In two siblings of another family, a large deletion of $14 q 13-q 13.3$ was associated with hyperthyrotropinemia, microcephaly, major feeding difficulties, and respiratory distress leading to the death of one of the sibs (19). In all three cases the deletion was present in only one allele but involved other genes, such as $P A X 9$. Thus it is not clear to what extent deletion of genes other than TTF1 contributed to the observed abnormalities. This and the accompanying contribution from Grüters's laboratory (20) describe heterozygous mutations within the TTF1 gene that cause predominantly neurological abnormalities.

\section{Methods}

Patient and other buman subjects. The propositus, a 6.5-year-old boy, is the second child of a nonconsanguineous marriage. He was born at term after a normal pregnancy but required mechanical ventilation for the first 2 weeks of life. Newborn screening revealed a TSH of $20 \mathrm{mU} / 1$ (upper limit of normal for age $=15 \mathrm{mU} / \mathrm{l}$ ) with normal free $T_{4}$ and $3,3^{\prime}, 5$-triiodothyronine concentrations, which remained in the mid-normal range when measured at $1,1.5,8,10$, and 48 months of age. During this period of time, serum TSH levels remained elevated, ranging from 7 to $21 \mathrm{mU} / 1$ (normal 0.3-4.5). He had delayed development, was hypotonic, and started walking at the age of 2 years with staggering gait. Height, weight, and head circumference ranged in the 3 rd to 10 th percentiles. The thyroid gland was normal in size and location by ultrasound, and brain magnetic resonance imaging showed no defects. Because of persistent elevation of $\mathrm{TSH}$ and an increase to $33 \mathrm{mU} / \mathrm{l}$ after administration of thyrotropin releasing hormone, treatment with $50 \mu \mathrm{g} \mathrm{L}-\mathrm{T}_{4}$ was begun at age 2.5 years. However, hypotonia worsened, and by age 4.5 years, the extrapyramidal symptoms became more apparent, manifesting choreiform hyperkinesia. Height, weight, and head circumference were at the 25 th percentile. A brother, older by 2 years, and both parents are healthy and do not exhibit any of the abnormalities observed in the propositus.

Blood samples were obtained from the propositus, his 8.5 -year-old brother, and their parents. DNA was collected from 50 unrelated individuals from the same ethnic background as controls. Studies carried out in humans were approved by the Institutional Review Boards of the Universities of Mainz and Chicago, and all individuals, or parents of minors, gave informed consent.

Mice. Animals were wild-type (+/+, 12 mice) and heterozygotes (+/-, 22 mice) for inactivated $T t f 1$ gene by targeted gene disruption, as described (11) They were of both sexes ( 19 female and 15 male), ranged in age from 8 to 14 weeks, and were littermates of six litters of heterozygous parents backcrossed 11 times into the 129/Sv strain. All animal manipulations were performed according to protocols approved by the Institutional Animal Care and Use Committees of the National Cancer Institute and the University of Chicago.

Coordination was evaluated by the Rotarod test used in mice (21), modified as follows. A motorized $36-\mathrm{mm}$ diameter wood rod was rotated at five incremental speeds of 5, 10, 15, 20, and $25 \mathrm{rpm}$. Starting at the lower speed, if the mouse could remain on top of the rod for 10 seconds by walking against the direction of the rotation, the speed was increased to the next incremental, until the mouse fell off the rod or spun around by gripping the rod. The time the mouse spent on the rod was recorded, and the mouse was given a second chance at the same rod speed. If the mouse failed again to remain on the rod for 10 seconds, the time was recorded and the average time of the two trials was retained. Mice that succeeded on the second trial were tested at the next speed as were mice that succeeded on the first trial. Scores of arbitrary relative distance were calculated, with maxima of $1,2,3,4$, and 5 at each of the five speeds if the mouse remained on the rod for 10 seconds. Distances at each speed were summed. All mice were tested five times over the period of 3 days. The person performing the test had no knowledge of the mice genotypes, and it was impossible to predict their genotypes from external appearances or behavior.

Blood samples (150-200 $\mu \mathrm{l})$ were obtained from the tail vein, under light methoxyflurane (Pitman Moore Inc., Mundelein, Illinois, USA) anesthesia. Serum was separated and used for the measurement of TSH and $\mathrm{T}_{4}$ concentrations (22). No samples were obtained during Rotarod testing.

DNA amplification and sequencing. Genomic DNA from all available family members and from 50 normal individuals was isolated from peripheral blood (QIAGEN Inc., Valencia, California, USA) after informed consent was given to participate in the study. The TTF1 gene was then amplified with primers flanking the three exons of the gene (PCR conditions and sequences of the primers will be supplied upon request). The PCR products were purified and sequenced using an automated sequencing system (A377; Applied Biosystems, Weiterstadt, Germany).

Construction of the vectors. The cDNA clone $12 \mathrm{~A} 2$ of the wild-type TTF1, in pRc/CMV (Invitrogen Corp., Carlsbad, California, USA), was obtained from Parviz Minoo (University of Southern California, Los Angeles, California, USA) (12). It was recloned into EcoRI site of pSG5 (Stratagene, La Jolla, California, USA) after removal of $171 \mathrm{bp}$ of the sequence preceding the translation start codon. The plasmid harbor- 


\section{Figure 1}

Identification of the mutation in the TTF1 gene and synthesis of the mutTTF1. (a) Fragments of sequence chromatograms of PCRamplified genomic DNA from a normal individual and the patient. Sense and the corresponding antisense sequences show the insertion of a $\mathrm{G}$ and a $\mathrm{C}$, respectively (arrows), at position 255 of the patient's TTF1 gene (numbering beginning with the first coding nucleotide in exon 2). The mutation involves one of the two alleles producing a "double" sequence beyond the insertion site. The encoded amino acids of wild-type and mutant TTF1 genes are indicated. (b) The deduced amino acid sequence of the mutTTF1 (divergent sequence in red) compared with the wtTTF1 (in black). The homeobox and the glutamine/alanine-rich regions of the WTTTF1 are boxed and underlined, respectively. Note that these sequences are lost in the mutTTF1, which has 36 additional amino acids. (c) The products of in vitro translation, analyzed by SDS-PAGE. One microgram of plasmid DNA containing the wild-type (dog and human) TTF1 and mutTTF1 cDNAs served as template in a coupled transcription/translation reaction in rabbit reticulocyte lysate in the presence of ${ }^{35} \mathrm{~S}-\mathrm{Met}$. The dried gel was then radioautographed. The larger size of the mutTTF1 was confirmed. A smaller amount of a lower-molecular weight product represents a product translated from a downstream ATG, as previously described (13). Molecular weights were deduced from the amino acid sequences. Wt, wild-type.

ing the mutation was generated by site-directed mutagenesis using the Quick Change kit (Stratagene). Both constructs were verified by sequencing. The construction of the reporter vector hTGenh/prm-Luc is based on the previously described $\mathrm{pBLCAT} 3$ vector containing an enhancer element and the promoter of the human thyroglobulin gene (23). These were removed from the original vector and ligated into the pGL3 basic plasmid (Promega Corp., Madison, Wisconsin, USA). The dog TTF1 expression vector, cloned into in PSG5 as described (14), was used as a control.

In vitro synthesis of TTF1 and electrophoretic mobility shift assay. The proteins of the wild-type TTF1 (wtTTF1) and of the mutant TTF1 (mutTTF1) were produced by in vitro transcription/translation using the TNT Coupled Reticulocyte Lysate System (Promega Corp.). Proteins were synthesized in the presence of ${ }^{35} \mathrm{~S}-\mathrm{Met}$, and the product was separated by 10\% SDS-PAGE. For electrophoretic mobility shift assay (EMSA), the in vitro translated proteins were mixed with a ${ }^{32}$ P-labeled oligonucleotide,

a sense

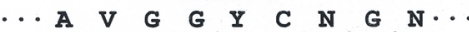
CCIGCCIG TGIGGGIGGCITACITGCIAACIGGCAAC WhWhWW Whowhond normal

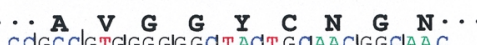
CQGCCD|GTGGGG|GGGTAMTG GAACGGCAAC

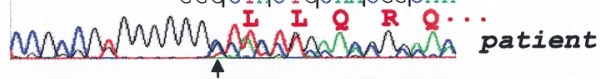
Insertion of a $\mathbf{G}$ at nucleotide 255

antisense

GT T|G CA|G T A| $\in$ C $q C C C|C A C| G G$ C $\mid G G$

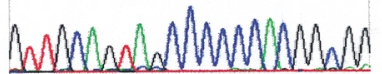

GT T|GC AlG TA|G C ClC C QC AdG GClGG

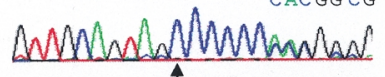

Insertion of a $\mathrm{C}$ at nucleotide 255

b

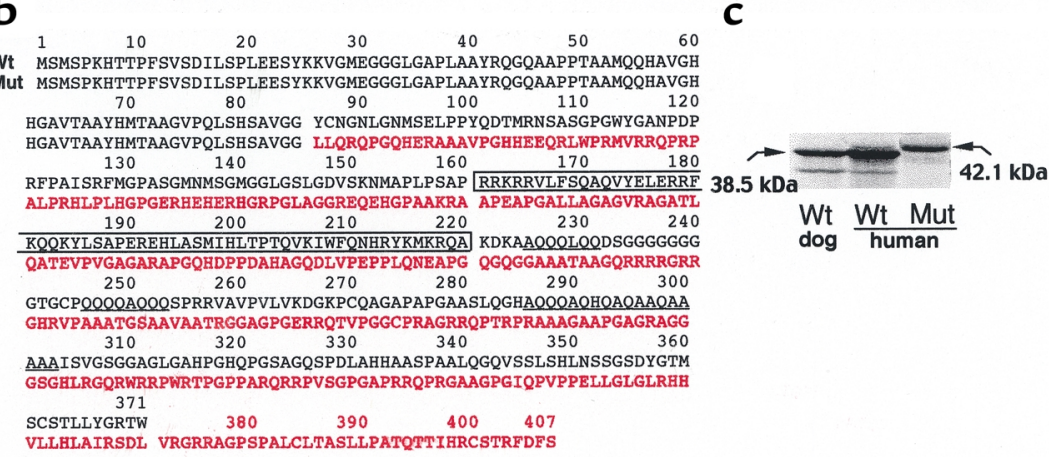

5'-CACTGCCCAGTCAAGTGTTCTTG-3' (oligonucleotide C) (24). Reactions were carried out in binding buffer containing $20 \mathrm{mM}$ HEPES, $50 \mathrm{mM} \mathrm{KCl}$ $20 \%$ glycerol, $1 \mathrm{mM}$ dithiothreiotol, $0.1 \mathrm{mg} / \mathrm{ml}$ poly[d(I-C)], and salmon sperm DNA. After 20 minutes' incubation at room temperature, the samples were separated on a $10 \%$ polyacrylamide gel at $200 \mathrm{~V}$ for 3 hours. The dried gel was transferred onto a filter paper and autoradiographed. A PhosphorImager (Storm 860 Optical Scanner; Molecular Dynamics, Sunnyvale, California, USA) was used for quantitative analysis.

In vitro functional assay. Human hepatoblastoma cells (HepG2) were grown in 12-well dishes in DMEM (Life Technologies Inc., Gaithersburg, Maryland, USA) supplemented with $10 \%$ bovine calf serum and $40 \mu \mathrm{g} / \mathrm{ml}$ gentamycin. Cells at $40-50 \%$ confluence were transfected with $1.5 \mu \mathrm{g}$ of plasmid DNA (normal, mutant, and empty/carrier vector, in different proportions) per well using the SuperFect reagent (QIAGEN Inc.). Forty-eight hours later the cells were harvested and analyzed for luciferase activity (Promega Corp.).

\section{Results and Discussion}

The combination of thyroid, lung, and brain involvement in the child prompted the analysis of the TTF1 gene. The rationale for this approach was admittedly weak considering that heterozygous Ttf1 knockout mice have been reported to have no apparent defects and homozygotes are born dead (11). Our patient had only a mild increase in serum TSH ranging from 7 to $21 \mathrm{mU} / 1$ (normal 0.3-4.5) with normal thyroid hormone levels and respiratory distress during the first 2 weeks of life. The most prominent clinical findings were neurological, consisting of hypotonia and dyskinesia that did not respond to thyroid hormone.

Sequencing of genomic DNA, from peripheral blood leukocytes of the child, revealed a heterozygous insertion of a guanine in codon 86 , producing a frameshift and a nonsense, abnormally long protein (a). The mutTTF1 contained 407 rather than the normal 371 amino acids, when translated from the first ATG in exon 2 (Figure $1 b$ ). This was confirmed by in vitro transcription and translation of the mutTTF1 (Figure 1c). His 


\section{a}

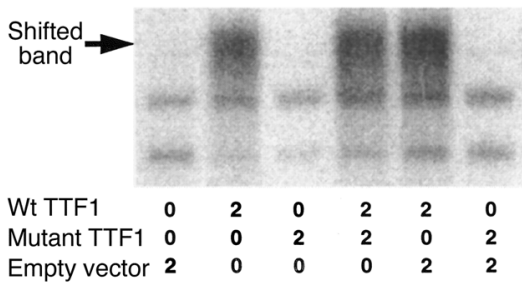

b

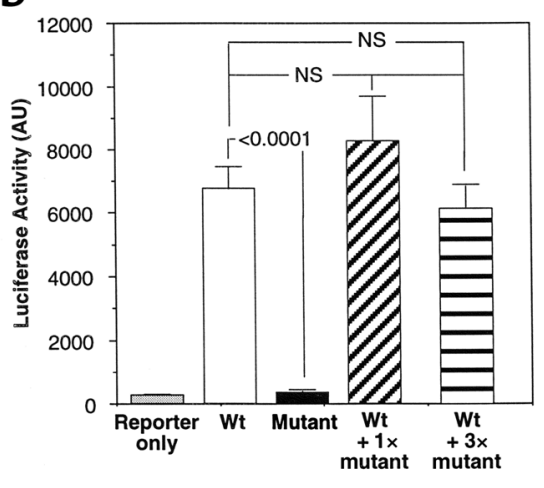

brother and parents, who were clinically normal and had normal serum TSH concentrations, as well as 50 unrelated normal individuals, did not harbor the mutation, indicating that the observed nucleotide insertion was not polymorphic and resulted from a de novo mutation event.

In order to characterize the mechanism by which this mutation causes the disease, we examined the mutant protein for its ability to bind to a canonical TTF1 cis-element and to activate the expression of TTF1-regulated genes in vitro. As shown in Figure $2 \mathrm{a}$, the mutTTF1 did not bind to the DNA sequence representing the full sequence of the high-affinity TTF1 binding site located in the rat thyroglobulin gene promoter (oligonucleotide C) (24) and containing the octamer consensus sequence for the TTF1 binding sites of rat, human, dog,

\section{Figure 2}

Functional analysis of the mutTTF1 as compared with the wtTTF1. (a) DNA binding was assessed by electrophoresis mobility shift assay using $\alpha^{32} \mathrm{P}$-labeled oligonucleotide primer (oligonucleotide C), containing the TTF1 binding sequence (see Methods), and TTF1 synthesized in reticulocyte lysate. The amounts of lysate (in $\mu \mathrm{l}$ ) added to each lane and its origin is indicated below the gel image generated by phosphorimaging of the electrophoresed gel. Note that the mutTTF1 does not bind to oligonucleotide $C$ and does not interfere with the binding of the wtTTF1. The same results were obtained with the addition of an equal amount (shown) and twice and four times the amount of the mutTTF1 as compared with wtTTF1 (see also Results and Discussion) (b) The transactivation properties of the mutTTF1 and wtTTF1 were tested by their cotransfection with a reporter luciferase expression vector driven by the human thyroglobulin enhancer/promoter. Note that the mutTTF1 completely lacks activity and does not interfere with that of the wtTTF1. AU, arbitrary units; $1 \times$ and $3 \times$, amount of mutTTF1 relative to wtTTF1.

and cow thyroglobulin and thyroperoxidase gene promoters (15). In addition, the mutTTF1 molecule did not interfere with the binding of the wtTTF1, when added in equal amounts (Figure 2a) and up to fourfold excess relative to the wild-type protein. The radioactivity in the shifted band produced by the wtTTF 1 in the presence of an equal amount, and twice and four times excess of the mutTTF1, was, respectively, 94\%, $123 \%$, and $109 \%$. These are expressed as percentages of the radioactivity generated with the wtTTF1 in the presence of the corresponding amounts of lysate reacted with unprogrammed vector. Furthermore, the mutTTF1 failed to transactivate the reporter driven by the thyroglobulin enhancer/promoter sequence or to interfere with the function of the wtTTF1 (Figure 2b). The lack of function of the mutTTF 1 is not surprising considering the complete absence of the homeobox amino acid sequence involved in DNA binding.

Because the in vitro experiments excluded a dominant negative effect as a mechanism for expression of the phenotype in the heterozygous patient, we sought to demonstrate haploinsufficiency by examining mice heterozygous for $T t f 1$ gene deletion. Based on anatomical and morphological studies, these mice were formerly considered to be normal (11). Upon examination by a standard test for motor coordination, $T \mathrm{tf} 1^{+/-}$mice had a mean \pm SEM Rotarod score of $1.87 \pm 0.23$, compared with that of $\mathrm{Ttf}^{+/+}$mice, $3.20 \pm 0.55(P<0.01)$ (Figure 3a). Similarly, as in the patient, the mean serum TSH concentration in $\mathrm{Ttf1}^{+/-}$mice was higher $(37 \pm 8 \mathrm{mU} / \mathrm{l})$ than in $T t f 1^{+/+}$mice $(7 \pm 3 \mathrm{mU} / \mathrm{l}$; $P<0.001$ ) (Figure 3b), whereas the serum $\mathrm{T}_{4}$ concentration was not different $(3.08 \pm 0.16$ vs. $3.42 \pm 0.45 \mu \mathrm{g} / \mathrm{dl}$, respectively) (Figure 3c). Furthermore, despite elevated serum TSH concentration, the thyroid gland size of $\mathrm{Tff}^{+/-}$mice was not significantly different from that of $T t f 1^{+/+}$mice, in absolute weight $(3.71 \pm 0.29$ vs. $4.30 \pm 0.87 \mathrm{~g})$ or corrected for body weight $(3.98 \pm 0.17$ vs. $4.62 \pm 0.58$ $\mathrm{g} / 25 \mathrm{~g})$. Thus, heterozygous Ttf1 knockout mice exhibit hyperthyrotropinemia with normal thyroid hormone levels and no goiter, but decreased coordination, findings similar to those observed in our patient.

While we cannot exclude a mild subclinical hypothyroidism as the cause for modest elevation of serum TSH concentrations despite normal
Figure 3

Effect of Ttf1 gene deletion in one allele $\left(T t f 1^{+/-}\right)$on neurological and thyroid function of mice. Results are expressed as mean \pm SEM. (a) Coordination was tested by the Rotarod test. $T t f 1^{+/-}$mice had significantly lower scores and, thus, worse coordination than wild-type littermates $(+/+)$. (b) $\mathrm{Ttf1}^{+/-}$mice had significantly higher serum $\mathrm{TSH}$ values than did $\mathrm{Ttf1} 1^{+/+}$ mice, but (c) the $T_{4}$ concentration was not significantly different. a

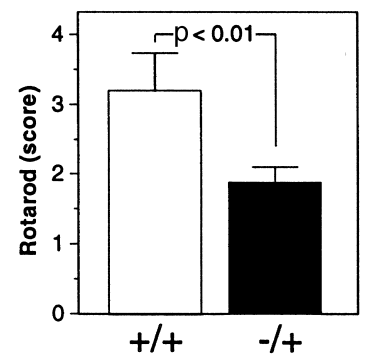

b

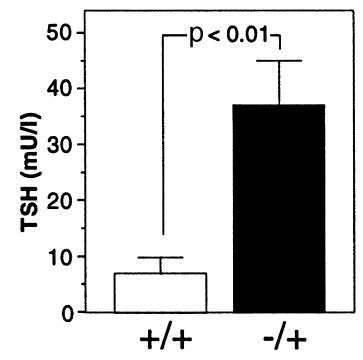

c

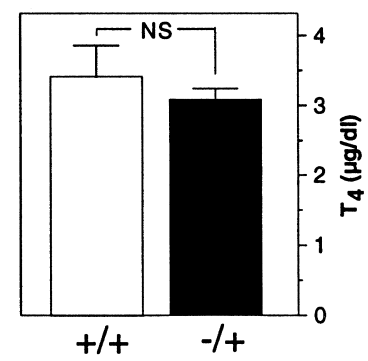


$\mathrm{T}_{4}$ levels, resetting of the feedback regulation of TSH due to a primary brain defect is a viable alternative explanation. The absence of goiter despite high serum TSH levels could be due to a reduced amount of TSH receptor, the expression of which is partially regulated by TTF1 (15). On the other hand, decreased stimulation by TSH-releasing hormone can produce a TSH of reduced biological activity (25). This could be caused by a hypothalamic defect and is compatible with the observation that TTF 1 is directly involved in the neuroendocrine regulation of sexual maturation (26). Unpublished work shows that various regions of the brains of $\mathrm{Ttf1}^{+/-}$embryos at embryonic days $12.5-18.5$ are morphologically normal at the gross level. These include the medial ganglionic eminence (anlage of the globus pallidus), hypothalamus (H. Kawano, L. Sussel, and J. Rubenstein); amygdala, hippocampus (S. Tole); cerebral cortex, thalamus, midbrain (H. Kawano); corpus callosum, hippocampal commissure, anterior commissure, internal capsule, neocortex, piriform cortex, and basal ganglia (K. Ohyama). Collectively, our data show that haploinsufficiency of TTF1 causes more severe neurological disturbance than thyroid dysfunction.

\section{Acknowledgments}

We thank all family members for their participation in this study; Daniel Christophe for provision of the dog TTF1 expression vector, the original CAT reporter construct, and oligonucleotide C; Parvis Minoo and Quiping Pan (University of Southern California, Los Angeles, California, USA) for the provision of the $12 \mathrm{~A} 2$ clone of TTF1 cDNA; Rusheng Zhang for helpful advice; and Sergio Alcoser for assistance with sequencing. We are also grateful to the following investigators for providing unpublished information regarding the neuroanatomy of $\mathrm{Ttfl}^{+/-}$mouse embryos: Hitoshi Kawano (Tokyo Metropolitan Institute for Neuroscience, Tokyo, Japan), Lori Sussel (University of Colorado, Health Science Center, Denver, Colorado, USA), John Rubenstein (University of California-San Francisco, San Francisco, California, USA), Shubha Tole (Tata Institute of Fundamental Research, Mumbai, India), and Kyoji Ohyama (Krebs Institute, Sheffield, United Kingdom). This work was supported by grants from $\mathrm{NIH}$ (DK-15070 to S. Refetoff and DK-58258 to R.E. Weiss) and the US Public Health Service (RR-00055) and by the Tivoli Wien Katz fund.

1. Refetoff, S., Dumont, J.E., and Vassart, G. 2000. Thyroid disorders. In The metabolic and molecular bases of inherited disease. Volume 3. C.R. Scriver et al., editors. McGraw-Hill. New York, New York, USA. 4029-4075.

2. Klett, M. 1997. Epidemiology of congenital hypothyroidism. Exp. Clin. Endocrinol. Diabetes. 105:19-23.

3. Poleev, A., et al. 1992. PAX8, a human paired box gene: isolation and expression in developing thyroid, kidney and Wilms' tumors. Development. 116:611-623.

4. Mansouri, A., Chawdhury, K., and Gruss, P. 1998 Follicular cells of the thyroid gland require Pax8 gene function. Nat. Genet. 19:87-90.

5. Macchia, P.E., et al. 1998. PAX8 mutations associated with congenital hypothyroidism caused by thyroid dysgenesis. Nat. Genet. 19:83-86.

6. Vilain, C., et al. 2001. Autosomal dominant transmission of congenital thyroid hypoplasia due to loss-of-function mutation of PAX8. J. Clin. Endocrinol. Metab. 86:234-238.

7. Zannini, M., et al. 1997. TTF-2, a new forkhead protein, shows a temporal expression in the developing thyroid which is consistent with a role in controlling the onset of differentiation. EMBO J. 16:3185-3197.

8. Chadwick, B.P., Obermayr, F., and Frischauf, A.M. 1997. FKHL15, a new human member of the forkhead gene family located on chromosome 9q22. Genomics. 41:390-396.

9. De Felice, M., et al. 1998. A mouse model for hereditary thyroid dysgenesis and cleft palate. Nat. Genet. 19:395-398.

10. Clifton-Bligh, R.L., et al. 1998. Mutation of the gene encoding human TTF-2 associated with thyroid agenesis, cleft palate and choanal atresia. Nat. Genet. 19:399-401.

11. Kimura, S., et al. 1996. The T/erp null mouse: thy- roid-specific enhancer-binding protein is essential for the organogenesis of the thyroid, lung, ventral forebrain, and pituitary. Genes Dev. 10:60-69.

12. Hamdan, H., et al. 1998. Structure of the human Nkx2.1 gene. Biochim. Biophys. Acta. 1396:336-348.

13. Guazzi, S., et al. 1990. Thyroid nuclear factor 1 (TTF-1) contains a homeodomain and displays a novel DNA binding specificity. EMBO $J$. 9:3631-3639.

14. Van Renterghem, P., Dremier, S., Vassart, G., and Christophe, D. 1995. Study of TTF-1 gene expression in dog thyrocytes in primary culture. Mol. Cell. Endocrinol. 112:83-93.

15. Damante, G., and Di Lauro, R. 1994. Thyroidspecific gene expression. Biochim. Biophys. Acta. 1218:255-266.

16. Lapi, P., et al. 1997. Mutations in the gene encoding thyroid transcription factor-1 (TTF-1) are not a frequent cause of congenital hypothyroidism (CH) with thyroid dysgenesis. Thyroid. 7:383-387.

17. Perna, M.G., et al. 1997. Absence of mutations in the gene encoding thyroid transcription factor-1 (TTF-1) in patients with thyroid dysgenesis. Thyroid. 7:377-381.

18. Devriendt, K., Vanhole, C., Matthils, G., and de Zegher, F. 1998. Deletion of thyroid transcription factor-1 gene in an infant with neonatal thyroid dysfunction and respiratory failure. $N$. Engl. J. Med. 338:1317-1318.

19. Iwatani, N., Mabe, H., Devriendt, K., Kodama, M., and Miike, T. 2000. Deletion of NKX2.1 gene encoding thyroid transcription factor- 1 in two siblings with hypothyroidism and respiratory failure. J. Pediatr. 137:272-276.

20. Krude, H., et al. 2002. Choreoathetosis, hypothyroidism, and pulmonary alterations due to human NKX2-1 haploinsufficiency. J. Clin. Invest. 109:475-480. DOI:10.1172/JCI200214341.

21. Raghupathi, R., et al. 1998. BCL-2 overexpression attenuates cortical cell loss after traumatic brain injury in transgenic mice. J. Cereb. Blood Flow Metab. 18:1259-1269.

22. Pohlenz, J., Weiss, R.E., Cua, K., Van Sande, J., and Refetoff, S. 1999. Improved radioimmunoassay for measurement of mouse thyrotropin in serum: strain differences in thyrotropin concentration and thyrotroph sensitivity to thyroid hormone. Thyroid. 9:1265-1271.

23. Donda, A., et al. 1993. Human, bovine, canine and rat thyroglobulin promoter sequences display species-specific differences in an in vitro study. Mol. Cell. Endocrinol. 90:R23-R26.

24. Civitareale, D., Lonigro, R., Sinclair, A.J., and Di Lauro, R. 1989. A thyroid-specific nuclear protein essential for tissue-specific expression of the thyroglobulin promoter. EMBO J. 8:2537-2542.

25. Beck-Peccoz, P., Amr, S., Menezes-Ferreira, M.M., Faglia, G., and Weintraub, B.D. 1985. Decreased receptor binding of biologically inactive thyrotropin in central hypothyroidism. Effect of treatment with thyrotropin-releasing hormone. N. Engl. J. Med. 312:1085-1090.

26. Lee, B.J., et al. 2001. TTF-1, a homeodomain gene required for diencephalic morphogenesis, is postnatally expressed in the neuroendocrine brain in a developmentally regulated and cell-specific fashion. Mol. Cell. Neurosci. 17:107-126. 